\title{
Cost, Availability and Distance as Correlates in Women's Access to Healthcare in Jere, Borno State, Nigeria
}

\author{
Esther Anenge Gbaden \\ (Dip. S.W.D., BSc., MSc., Assistant Lecturer) \\ Department of Sociology/Anthropology University of Maiduguri, P.M.B. 1069, Maiduguri Borno State, Nigeria
}

\begin{abstract}
This sociological study reports the results of a research carried out in 2007 to ascertain the ways in which financial cost of healthcare, availability of health service centres and distance to such facilities act in hindering women's' accessibility to healthcare in Jere Local Government Area of Borno State, Nigeria. The women are mostly housewives, with minimal education and consequently low social status as such their inaccessibility to appropriate healthcare. Data gathering was via questionnaire administration and in-depth interviews. The quantitative and qualitative data were analysed by descriptive statistics of frequencies, and percentages. The findings indicate that, distance, cost and availability of services and facilities have effect on women's access to healthcare. Recommendations are that government should integrate women's position in healthcare policies, provide subsidies for healthcare and as well work towards an even spread of health facilities and services.
\end{abstract}

Key Words: Women, Healthcare, Availability, Cost, Distance, Barriers, Jere, Access.

\section{Introduction}

Availability of health services tend to affect accessibility in no small measure, women especially poor rural ones may have to walk very long distances to get to the nearest health facilities. Even where location of these facilities or services does not necessarily stand as a barrier in terms of proximity the cost of these may weigh heavily on women's decision to use available services. Moreover, as argued variously by Lennox (1984), Stock (1983) and Freeman et al (1983), the distance separating patients from the nearest health facility has proven to be an important barrier to seeking access to health care, particularly in rural areas. As separate factors the effect of any one of these factors cannot be over emphasised but when put together the effect gets more intense as women will not only have to travel long distances to access healthcare but may also have to worry about the cost effect of doing so.

\section{Objectives}

The objective of the research work was to ascertain the ways in which financial cost of healthcare, availability of health services and facilities and distance to such facilities act in hindering women's accessibility to healthcare in Jere Local Government Area of Borno State, Nigeria.

\section{Literature Review}

\section{Cost: A Correlate of Accessing Healthcare}

The cost of healthcare is likely to weigh heavily on a woman's decision to use available services. Evidence from around the world has shown that user fees and other charges for services tend to have a negative impact on utilization. It is likely that user fees deter women from booking hospital deliveries. In general, the poorer women are, the more likely are charges to affect their likelihood of using services. Work in Cote d'Ivoire (Gertler and Vander Gaag, 1988) and Peru (Gertler et al, 1988) has shown that user fees deter any one from using services but they deter the poor most of all.

Financial cost of receiving care, which includes transportation cost, physician and facility fees (when they exist) and the cost of medications and other supplies cost and distance often go hand in hand as considerations in the decision making process as longer distance entails higher costs.

The cost of medicines is most likely to affect compliance with prescribed treatment. However, to the extent that the cost of drugs figures in the decision to seek care, it can be expected to delay or discourage that decision.

That notwithstanding, cost as a factor of accessing healthcare is very important as the financial cost of health services in the form of provider fees and the price of medication are only some of the cost considerations facing individuals in their decision to access healthcare. The other important component is the opportunity cost of the time used to seek health services which according to the World Population Monitoring 1998 is the value of what could have been produced in that time had it been used differently. Time spent getting to, waiting for 
and receiving health services is time lost from other more productive activities such as farming, fetching water and wood for fuel, herding, cooking, trading or engaging in other employment. As women carry out a large majority of these tasks the value of their time and the competing demands made on it assume critical importance in the decision to access healthcare. Finding time to attend a pre-natal clinic for instance is unlikely to rank high in the order of priorities particularly for women or parts of the world that view pregnancy and childbirth as a normal life event not requiring special care, (Bedics, 1994; Pino \& others 1991).

Dor and Vander Gaag (1988), using data from the Ivorian Living Standard Survey (ILSS) showed that in the absence of health services fees, the demand for health care is effectively rationed by other "Private Costs". These costs, they argue, play the role of the conventional price mechanism in limiting people's utilization of health services. The "Private cost" of travel time to the nearest provider was found to be a particularly strong determinant of utilization. Thus although medical care is free of charge in the Ivory Coast, transportation costs and the time to reach a facility are high. Moreover, in many parts of the developing world, prospective patients, especially women, do not travel alone to a health facility: they are accompanied by other adults and by children who cannot be left at home alone because caretakers are not available. All these additional people swell the cost of transport.

Foster (1977) for instance pointed out the under utilization of free healthcare and family planning services in Indonesia to the opportunity costs involved in reaching them. When they decided to visit a clinic, Indonesian women often had to take their younger children along because they had no one with whom to leave them. This entailed not only additional bus fares, but also the provision of snacks for all, so a mother with three or four small children may well spend a day's income on a single visit to the 'free' clinic. The availability of others to help with household chores, to look after children or to accompany patients to the facility can be a factor in the decision to seek or access healthcare.

\section{Availability of Healthcare Facilities}

Coverage of health facilities especially in rural areas remains a big barrier to access. Due to the unavailability of facilities, poor women in rural areas often walk more than an hour to the nearest health facility. Poor road infrastructure and lack of public transport make access difficult especially when there are complications. As a result a poor woman will seek healthcare from less trained providers who are more accessible.

Jegede (2002) observed that location of health facilities had been a major source of problem to healthcare delivery in Nigeria. Since Nigeria health policy is curative and hospital based health facilities are mostly not within the reach of the poor people, majority of whom encounter problems in their day to day subsistence activities. They have little or no access to healthcare and where they have at all, the cost of such provision is enormously high. The disparity in the distribution of health care facilities indicates a bias in favour of the urban centres.

\section{Distance to Healthcare Facilities}

The distance separating potential patients from the nearest health facility has proven to be an important barrier to seeking access to healthcare, particularly in rural areas, as opined by Freeman et al (1983), Lennox (1984), and Stock (1983).

Long distance apart from actual obstacles to reaching a health facility can also be disincentive to even trying to seek care. Further, the effect of distance becomes stronger when combined with lack of transportation and poor roads.

Pramparo (2000), states that delay in access to care due to lack of transport is a factor strongly related to economic resources. And according to Nwakoby et al (1997) this contributes to maternal mortality as it revealed delays in seeking and reaching emergency care for pregnant women when needed. Delay in arrival due to long distances has also been documented by El-Nafaty and Omotara (1998); Talamanca (1996); Crichton and Knobel (1998); and Justesen (1995). In fact, transportation problems are likely to be more important in rural settings.

The impact of distance as a consideration in accessing and subsequently utilising health services has been assessed in a variety of ways. The impact has been most directly determined when provided by people in interviews in the facility or in the community, as indicated by Orubuloye and Caldwell (1975). According to the duo, two Nigerian villages who had not used a health facility to give birth suggested that difficulty of travelling to a health centre was an important consideration. In the said study $96 \%$ of women from a total number of 119 in a village without local health facility gave distance as the reason for not having hospital deliveries, $64 \%$ also cited distance or the related cost of transportation as the reason for non-use of health facilities even in their last illness episodes. In another village with a local hospital, only $12 \%$ of the women not using the facility for delivery gave distance as the reason. 
Egunjobi (1983) in a survey of 859 hospital patients in Oyo State saw distance ranking first among factors affecting choice of hospital with $32 \%$ of respondents saying it was the most important consideration in their decision to access health.

In determining access, attendance records at a diarrhoea treatment centre in Bangladesh were used to evaluate the utilisation of the facility. Almost all patients living within one mile of the centre used its services indicating that they had and could access the facility. However attendance fell sharply for patients living more than a mile from the centre and differentials by gender became apparent, with more males using the centre than women. At a distance of two miles attendance dropped to $70 \%$ for males and to $40 \%$ for females (Rahaman et al, 1982).

From the foregoing, it can be concluded that the farther away people live from a health facility the less likely they are to use it especially for women that almost always have enormous tasks to carry out.

\section{Methodology}

This section deals with the study setting, the methods used in collecting and analysing data, as well as the logic for using these methods.

\section{Study Setting}

The study was conducted in Jere Local Government Area of Borno State, Nigeria. Jere is one out of the twenty seven (27) Local Government Area Councils of Borno State (Federal Republic of Nigeria Official Gazette, 2007). The creation of Jere Local Government Area, created out of Maiduguri Metropolitan Council in 1996, which consists of fourteen (14) wards, a total Population of 211204 out of which 102598 are women, bore out of the desire by the Federal Government to ensure an even spread of development oriented programmes throughout the federation (Jere Local Government Council Dairy, 2006).

Covering a land mass of about 160 square kilometres, Jere is largely rural; this explains the prevalence of primary activities like cattle rearing, nomadic farming, fishing, and crop farming that includes such crops as millet, guinea corn, beans, onion, okra, as well as irrigation farming. Prominent ethnic groups here are Shuwa, Kanuri and sprinkles of Hausa and Fulani and other migrant ethnic peoples. Despite the situation of the University of Maiduguri in Jere, an average Jere woman is illiterate and for economic activities engages in farming, cattle rearing, trading (in rice, cattle, sheep, camels and their bye products) and as well as plaits, sews and does Henna/Lele body decoration; all on petty basis.

A lot of religious and cultural festivals are celebrated in Jere. Predominant among them are the Sallah festivals (Eid-el-Kabir, Eid- el-Maulud, Eid-el-Fitr), turbanning/chieftaincy title taking ceremonies. These attract people from far and near as they converge to see the Durbar (horse riding) that usually goes along with the celebrations. Circumcision festivals, marriage and naming ceremonies and graduation from Quranic recitation schools are other ceremonies that are well celebrated. There is female Genital mutilation among the Shuwa Arabs of Jere, this is done between the ages of 3-6 years and is said to reduce sexual stimulation thus restricting girls from engaging in premarital sexual liaisons and also helps to keep them faithful to their husbands during marriage.

The marriage pattern among the Shuwa, Kanuri and Hausa/Fulani who are predominantly Muslims follows the Islamic tenet where a man is allowed to take up to four wives if he can indeed carter for them. However polygyny as argued by Miller and Rockwell (1988) exposes women to health risks. Also marriage age according to this researcher's informants is between the ages of 13 to 15 years for girls and from 18years for boys. This relatively young marriage age may as well have negative health implications for women. Drinking of Quranic slate writing is a cultural practice among Jere people of Islamic inclination. The drinking of the charcoal based ink used to inscribe relevant verses of the Quran is said to enhance pregnancy and it also helps in safe delivery.

Almost all the wards have one form of health facility or the other that provide services ranging from immunization, maternity to more complex health problems that are mostly handled by the University of Maiduguri Teaching Hospital (UMTH) located in Mairi ward.

\section{Research Design}

The study adopted the survey design. Both descriptive and analytical approaches were considered in the choice of the methods of collecting and analysing data; the qualitative and quantitative instruments were used in collecting data.

\section{Study Population}

The study population for the survey research consisted of middle aged women (age range 40-65), domiciled in Jere Local Government Area of Borno State. Women of different economic, educational, religious 
and marital status where involved in the study to bring to bear the fact that, though cultural and religious factors affect women's access to healthcare, they do so differently.

\section{Sample and Sampling Techniques}

The sample size for the study consisted of 360 women. To make for good representation of Jere Local Government Area, the multistage sampling technique was used in selecting respondents. First, the about hundred villages that make up the fourteen wards of Jere were clustered into twenty blocks of each five naturally occurring villages. Second, communities for the study were selected through balloting where one community was selected from each of the twenty blocks or zones. The third stage saw the random selection of ten villages from the selected communities. Then systematic random technique was used in selecting households that were finally chosen for the study. From the selected households in each village 36 women aged 40-65 and above were randomly selected for the administration of the questionnaire. The qualitative aspect of the study consisted of fifteen interviews; this incorporated the varying categories of women and by implication afforded the flexibility denied by the structured questionnaire.

\section{Research Instruments}

The study employed the use of both qualitative and quantitative methods of data collection. This involved the use of questionnaire and in-depth interview. These provided holistic, rich and complimentary data and insight on distance, cost and availability of facilities as they bother on women's access to healthcare in the area of study.

\section{Administration}

The questionnaires were administered by the researcher with the aid of research assistants trained for the purpose of the study.

\section{Methods of Data Analysis}

Use was made of the Statistical Package for Social Sciences (SPSS) for the statistical analysis of data collected through questionnaires. Even though 360 questionnaires were administered 10 of them were invalidated for reasons of illegibility and incompleteness. Descriptive statistics of frequency tables and percentages were used to describe the responses on each of the variables. Information from the in-depth interviews were transcribed into written words and analysed using ethnographic summaries and content analysis whereby the central points made by interviewees are quoted and the points arising thereof discussed.

\section{Ethical Consideration}

The Principles of ethics involved in human research were strictly adhered to. Due to the nature of the study, which deals with the cultural and religious practices of the respondents involved it became apparently important to adhere to ethical standards. The researcher sought and obtained the approval of the religious leaders, village heads otherwise known as Lawan or Bulama, before data collection for the study began. The consent of the respondents were also sought and obtained.

\section{Data Presentation and Discussion}

Table 1: Bio data of respondents

\begin{tabular}{|c|c|c|c|}
\hline \multirow{3}{*}{ Characteristics } & Category & Frequency & Percentage \\
\hline \multirow{4}{*}{ Age } & & 160 & 45.7 \\
\cline { 2 - 4 } & $40-44$ & 78 & 22.3 \\
\cline { 2 - 4 } & $45-49$ & 84 & 24.0 \\
\cline { 2 - 4 } & $50-54$ & 20 & 5.7 \\
\cline { 2 - 4 } & $55-59$ & 8 & 2.3 \\
\hline & $60-$ above & 350 & 100.0 \\
\hline
\end{tabular}


Cost, Availability and Distance as Correlates in Women's Access to Healthcare in Jere, Borno....

\begin{tabular}{|c|c|c|c|}
\hline & Category & Frequency & Percentage \\
\hline \multirow[t]{4}{*}{ Religious Affiliation } & Christianity & 47 & 13.4 \\
\hline & Islam & 300 & 85.7 \\
\hline & Traditional Afr. Rel. & 3 & 0.9 \\
\hline & Total & 350 & 100.0 \\
\hline \multirow[t]{5}{*}{ Ethnic Group } & Shuwa & 157 & 44.8 \\
\hline & Kanuri & 85 & 24.3 \\
\hline & Hausa & 66 & 18.9 \\
\hline & Others & 42 & 12.0 \\
\hline & Total & 350 & 100.0 \\
\hline \multirow[t]{5}{*}{ Marital Status } & Married & 307 & 87.7 \\
\hline & Divorced & 7 & 2.0 \\
\hline & Widowed & 10 & 2.9 \\
\hline & Separated & 26 & 7.4 \\
\hline & Total & 350 & 100.0 \\
\hline \multirow[t]{4}{*}{ Married Type } & Monogamy & 58 & 16.6 \\
\hline & Polygyny & 252 & 72.0 \\
\hline & Non-Response & 40 & 11.4 \\
\hline & Total & 350 & 100.0 \\
\hline \multirow[t]{4}{*}{ Form of Education } & Formal & 107 & 30.6 \\
\hline & Quranic & 170 & 48.5 \\
\hline & Formal and Quranic & 73 & 20.9 \\
\hline & Total & 350 & 100.0 \\
\hline \multirow[t]{6}{*}{ Level of Education } & Basic Quranic & 161 & 46 \\
\hline & Primary & 71 & 20.3 \\
\hline & Secondary & 96 & 27.4 \\
\hline & Tertiary & 20 & 5.7 \\
\hline & Non-Response & 2 & 0.6 \\
\hline & Total & 350 & 100.0 \\
\hline \multirow{5}{*}{ Occupation } & Farmer & 42 & 12.0 \\
\hline & Trader & 69 & 19.7 \\
\hline & Civil Servant & 34 & 9.7 \\
\hline & House Wife & 205 & 58.6 \\
\hline & Total & 350 & 100.0 \\
\hline
\end{tabular}

Table 2: Distribution of respondents according to the factors that affect women's access to healthcare

\begin{tabular}{|l|c|c|c|c|c|c|}
\hline \multicolumn{1}{|c|}{ Factors } & \multicolumn{2}{c|}{ Agree } & \multicolumn{2}{c|}{ Disagree } & \multicolumn{2}{c|}{ Don't know } \\
\hline & Frequency & $\mathbf{\%}$ & Frequency & $\mathbf{\%}$ & Frequency & $\mathbf{\%}$ \\
\hline Unavailability of facilities & 159 & 45.4 & 140 & 40.0 & 51 & 14.6 \\
\hline Cost of receiving healthcare & 185 & 52.9 & 157 & 44.9 & 8 & 2.3 \\
\hline Cultural practices & 82 & 23.4 & 203 & 58.0 & 65 & 18.6 \\
\hline Religious practices & 101 & 28.9 & 191 & 54.6 & 58 & 16.6 \\
\hline Distance & 153 & 43.7 & 138 & 39.4 & 59 & 16.9 \\
\hline
\end{tabular}

Source: Field Survey 2007

In table 2 above, respondents were asked to indicate factors that affect women's access to healthcare in Jere. $142 \%$ agreed that distance to health facilities, cost of receiving healthcare and availability of facilities affect women's access to health in Jere. Thus even though about 91.15 of the total respondents reported the awareness of healthcare facilities in their localities, access may be poor since the issue of accessibility goes beyond having knowledge of facilities to how far apart they may be located from the people as well as how affordable they may be.

To determine the Level of access to healthcare services, respondents were asked to indicate if they always used healthcare services when they needed them. $61.1 \%$ of the total respondents reported that they do not always use healthcare services when they need them.

Table 3: Distribution of respondents according to proximity to health facilities

\begin{tabular}{|l|l|l|}
\hline \multicolumn{1}{|c|}{ Proximity to health facilities } & Frequency & \% \\
\hline $2 \mathrm{~km}$ away from health facility & 162 & 46.3 \\
\hline $6 \mathrm{~km}$ away from health facility & 88 & 25.15 \\
\hline $10 \mathrm{~km}$ away from health facility & 12 & 3.4 \\
\hline $20 \mathrm{~km}$ away from health facility & 88 & 25.15 \\
\hline TOTAL & 350 & 100 \\
\hline
\end{tabular}

Source: Field Survey 2007

The proximity of healthcare facilities to place of residence was also used as a determinant of access to healthcare. The data above showed that $53.7 \%$ of the total respondents live further then $2 \mathrm{kms}$ away from the 
hospital while only $46.3 \%$ of the respondents live at a distance of about $2 \mathrm{~km}$. Given the "Nigerian factor", the distance of $2 \mathrm{~km}$ (which is the same as going round a standard football pitch twenty times) away from a healthcare facility in a rural area may be seen to be good without the interference of other factors, but in an area where the road network is not very good, as is always the case with rural areas walking that distance may result in the death of the mother and or baby due to resultant complications from delay in arrival at healthcare facilities. Moreover research has also proven that, for a woman with obstetric complications, access limited to nearby primary healthcare centres is not of much help since these facilities are not equipped to deal with obstetric complications (Kloos 1987). This is in line with the reports by two of the interviewees, age categories 45-49 and 55-59.

"The health services here are basically primary and not able to handle complicated diseases. In fact most of the centres do not function at night and even simple things like ruwa (drip) are hardly available."

"We do not talk of emergency here, when you come to hospital here you pray the doctors will come early, if not you will wait till when they are available, the most important thing is that you are able to see a doctor at the end of the day."

Respondents were also asked how frequently they visited healthcare facilities. This was to determine if the distance talked about had effect on them. The results are indicated on table 4, below.

Table 4: Level of visits to healthcare facility

\begin{tabular}{|r|c|c|}
\hline \multicolumn{1}{|c|}{ Level of visit to health facility } & Frequency & Percentage \\
\hline Very Regular & 43 & 12.3 \\
\hline Regular & 78 & 22.3 \\
\hline Not Regular & 229 & 65.4 \\
\hline
\end{tabular}

Source: Field Survey 2007

The data above indicates that $65.4 \%$ of the respondents do not visit the available healthcare facilities regularly with only $12.3 \%$ being very regular. The data from the in-depth interview collaborated with the report on poor access in the following way as asserted by a respondent from the age grade $40-44$.

"The state of access is low since majority of women here are stopped from using health facilities due to one reason or the other, ranging from spousal objection, lack of money, unavailability of facilities to restriction of movement."

Apparently, where visitation to healthcare facilities is low, utilisation is not possible and so access may be considered to be low and may therefore have resultant effect on women as well as their family members.

Table 5: Distribution of respondents by consequences of women's inaccessibility to healthcare

\begin{tabular}{|l|c|c|}
\hline \multicolumn{1}{|c|}{$\begin{array}{c}\text { Consequences of women's } \\
\text { inaccessibility to healthcare }\end{array}$} & Frequency & Percentage \\
\hline High maternal morbidity & 60 & 29 \\
\hline High maternal mortality & 101 & 31 \\
\hline Poor state of health & 108 & 23 \\
\hline High infant and child mortality & 81 & $\mathbf{1 0 0}$ \\
\hline Total & $\mathbf{3 5 0}$ & \\
\hline
\end{tabular}

Source: Field Survey 2007

The data on table 5 show responses of respondents when asked based on the most commonly experienced to indicate the consequences of women's inaccessibility to healthcare. Poor state of health is the most common consequence of women's inaccessibility to healthcare, followed closely by high mortality.

\section{Conclusion}

Access to healthcare is the right of all humans but most significantly that of women, this becomes even more important if the human race will be perpetuated, cultures be transmitted and young ones be socialised properly into the society.

Provision of health services and facilities that are affordable in all sense of the word and that are within the reach of all women whether they be in urban or rural areas is highly needful, however, this will require putting into health studies and policies women's position as it bothers on their health and healthcare. 


\section{Recommendations}

Government should integrate women's perspective into health policies for the achievement of their coverage in the health system.

Subsidization of health services for women is highly recommended as this function to bridge the gap between the affluent and indigent women who may not be able to afford exorbitant health costs. Government should work towards an even distribution of health services and facilities especially in the rural areas as that will go a long way to solve the problem of long distance trekking and its attendant problems.

Health personnel and hospital management should seek innovative ways of promoting coverage; adjustment in timing of health centres, provision of services in long with markets, church, mosques activities.

\section{References}

[1]. Bedics, B. (1994). Non-use of Prenatal Care: Implications for Social Work Involvement. Health and Social Work. (Washington, D.C.). Vol. 19, No. 2(May): 84-92.

[2]. Crichton, D. and Knnobel, J. (1973). The Principles of Prevention of Avoidable Maternal Deaths. $\quad$ South African Medical Journal. 47:2205-2210.

[3]. Dor, A., and J. Vander Gaag. (1988). The Demand for Medical Care in Developing Countries- Quantitative Rationing in Rural Cote d'Ivoire. Living Standards Measurement. Washington $\quad$ D.C.: World Bank Study LSMS Working Paper No. 35

[4]. Egunjobi, L. (1983). Factors Influencing Choice of Hospitals: A Case Study of the Northern Part of Oyo State. Social Science and Medicine. 17(9): 585-589.

[5]. El-Nafaty, A.V. and B.A. Omotara. (1998). Perceived Causes of Eclampsia in Four Ethnic Groups in BornoState,Nigeria. African Journal of Reproductive Health. 2(1-2): 20-25.

[6]. Freeman, D.H. Jr., et al. (1983). A Categorical Analysis of Contacts with the Family Health Clinic. Calabar: Social Science and Medicine. 17(9):571-578.

[7]. Foster, G. (1977). Medical Anthropology and International Health Planning. Oxford: Social Science and Medicine. 11:527-534.

[8]. Jegede, A. S. (2002). Problems and Prospects of Health Care Delivery in Nigeria: Issues in Political EconomyandSocial Inequality. Isiugo-Abanihe. (Ed.)Currents and Perspectives in Sociology. Ibadan: Malthouse Press Limited.

[9]. Justesen, A. (1995). An Analysis of Maternal Mortality in Muhimbilli Medical Centre. Davees Splaar. Obstetricsand Gynaecology. East Central Africa. 4:5-8.

[10]. Lennox, C.E. 1984. Assessment of Obstetric High Risk Factors in a Developing Country. Tropical Doctor.

[11]. Nwakoby, B., Akpala, C., Nwagbo, D., Onah, B., Okeke, V., Chukwudebelu, W., Ikeme, A., Okaro, J., Egbuciem, P., and A., Ikeagu. (1997). Community Contact Persons Promote Utilisation of Obstetric Services, Anambra State, Nigeria. Enugu PPM Team. International Journal of Gynaecology and Obstetrics. 59(2): 5219-5224.

[12]. Orubuloye, I.0. and J.C., Caldwell. (1975). The Impact of Public Health Services on Mortality: A Study of Mortality Differentials in a Rural Area of Nigeria. Population Studies. 29(2):259-272.

[13]. Pino, A. and Others. (1991). Mortalidad Materna en el Ecuadoy Aspectos Culturales en la atencion de laMujer embrazada. Revista del I-Institulo Juan Cesar Garcia (Quito, Ecuador) Vol. 1, No. $\quad$ 1(Jan): 33-56.

[14]. Pramparo, P. (2000). Diagnosis, Treatment and Access to Care. The First International Conference on Science and Policy in Action. 1 of 6.

[15]. Rahaman, M., et al. (1982). A Diarrhoea Clinic in Rural Bangladesh: Influence of Distance, Age, Sex on Attendance and Diarrheal Mortality. American Journal of Public Health. 72(10): 1124-1128.

[16]. Stock, R. (1983). Distance and the Utilisation of Health Facilities in Rural Nigeria. Social Science and Medicine. 17(9): 563-570.

[17]. Talamanca, I.F. (1996). Maternal Mortality and the Problem of Accessibility to Obstetric Care; The Strategy, Maternity Waiting Homes. Social Science and Medicine. 427 (10):1381-1389. 